DOI: http://dx.doi.org/10.22483/2177-5796.2018v20n3p721-737

\title{
Uma aprendizagem lenta da vida
}

\author{
Vivian Marina Redi Pontin
}

Resumo: O pequeno espaço dessa escrita interessa-se por adentrar na construção de um pensamento. Nele, escola e educação física são os territórios privilegiados para indagar suas funções sociais. A aprendizagem e o fundamento possuem a incumbência de serem maneiras de aproximar-se do que podem tais territórios. Diante de inúmeras imprevisibilidades que essa construção e o caminho aqui escolhido podem gerar, a atenção se direciona para os afetos que rodeiam os encontros dos corpos e as seleções daquilo que lhes convém. Sobre as transformações que os conteúdos da educação física precisam sofrer para estarem presentes no espaço e tempo escolares, há uma implicação naquilo que se entende por aprender e naquilo que se inventa ao pensar uma cultura. Enfim, trata-se de maneiras de perceber o mundo, suas relações e articulações naquilo que foge do controle absolutamente e sua difícil mensuração - uma vida.

Palavras-chave: Aprendizagem. Educação física. Afeto.

\section{A slow learning of life}

Abstract: The small space of this writing is interested on get in the construction of a thought. In it, school and physical education are privileged territories to investigate their social functions. Learning and grounding have the task of being ways of approaching what can such territories. Before the innumerable unpredictability that this construction and path chosen here can generate, the attention is directed toward affects that surround the meetings of bodies and the selection of what suits them. About transformations that the contents of physical education must suffer in order to be present in school space and time, there is an implication in what is meant by learning and what is invented when thinking about a culture. Finally, it is about ways of perceiving the world, its relations and articulations in what escapes from control absolutely and its difficult measurement - a life.

Keywords: Learning. Physical education. Affect. 


\title{
Introdução
}

\begin{abstract}
Alguém me disse que um livro de poesia é diferente. É uma máquina muito mais rápida. A cada vez que passa, passa de outra maneira. Deve ter pés estranhos (TAVARES, 2005, p. 7-8).
\end{abstract}

Um dos objetivos da educação física escolar apontado na coletânea organizada por Suraya Darido e Irene Rangel (2011) é garantir a autonomia dos alunos, e ela se define por uma série de aspectos, dos quais são elencados os seguintes: de que a autonomia é alcançada pela condição de manutenção numa atividade física, pela negação da violência nas manifestações sociais, pela apreciação espetacular, pelo reconhecimento de características adequadas nos locais de prática de atividade, pelo posicionamento sobre os padrões de beleza colocados nas mídias, pela participação em atividades nos horários de lazer, pelas relações que se pode estabelecer entre a fisiologia do exercício e sua prática.

A autonomia é, então, garantida porque o professor é capaz de proporcionar determinadas ações, as quais decorrem certas atitudes em relação às práticas da cultura corporal. Quanto maior a vivência das diferentes práticas e a compreensão do seu papel na sociedade, maior também a autonomia do aluno em relação a elas.

É claro que esse não é o único objetivo da educação física escolar apontado na coletânea, no entanto há uma insistência nesse aspecto da autonomia, uma espécie de senso comum para essa área de conhecimento e de intervenção pedagógica.

Uma das coisas que se gostaria de salientar sobre esse ponto é que os aspectos definidores do que seria ter autonomia geralmente se colocam num tempo futuro e fora do espaço escolar, portanto, ao adquirir autonomia, o aluno estará apto para, nos locais em que estiver fora do tempo e espaço escolar, escolher as práticas da cultura corporal que lhe convier, bem como portar-se bem dentro dessa prática.

De forma alguma se quer, aqui, negar a importância da autonomia. Mas será que ela é mesmo um objetivo? Ou será que dela decorre aquilo que é construído nas aulas de educação física? Se assim for, a autonomia não é realmente um objetivo, mas uma possibilidade diante do que se faz no cotidiano escolar. 
PONTIN, Vivian Marina Redi. Uma aprendizagem lenta da vida.

E sendo possibilidade, a autonomia pensada como ação de orientar-se por si mesmo, seus frutos não são colhidos fora do tempo e espaço escolar, mas é desde dentro das aulas que a autonomia é exercida pelos alunos, porque construída nas configurações próprias da aula de educação física. O que acontece fora desse tempo e espaço pode até ser chamado de autonomia, mas ela não é construída a partir das aulas de educação física, mas com essas aulas, aquilo que nela afeta as crianças e jovens, somado ao contexto social em que as práticas da cultura corporal são lá exercidas.

O que se está aqui construindo é um pensamento sobre a função social da escola. A escola não é uma preparação para a convivência social, uma preparação para a autonomia social, mas, antes, um lugar em que a convivência e a autonomia são experimentadas.

A autonomia, portanto, não é uma replicação do que a escola e a educação física têm por objetivo, mas, assim como a convivência e o compartilhamento nas dinâmicas sociais, ela é construída a cada vez dentro do campo em que está inserida.

Dessa forma, há uma avaliação por parte dos indivíduos que compõem um campo de atuação social, dentre eles a escola, e, arrisca-se dizer, que é com essa avaliação de forças que a escola e também a educação física se ocupam. Quais são as forças que estão em jogo dentro de determinada proposta em aula ${ }^{1}$ ?

E dizer que a escola e a educação física se ocupam dessa avaliação de forças, isso não está centralizado na figura do professor ou do diretor, mas de todos os atuantes (LATOUR, 2001) ${ }^{2}$ que participam desse espaço e tempo.

Para tentar explicar essa ideia das forças que atravessam um corpo e de sua avaliação, toma-se como exemplo a ideia de um cheiro. Determinado cheiro pode ser sentido de diferentes maneiras, sendo, ainda, o mesmo. Isso não só porque os narizes possuem potências diversas, alguns são mais propensos aos cheiros do que outros, há toda uma anatomia que favorece e desfavorece, há quantidades de receptores diferentes, enfim, uma série de explicações a partir dos

\footnotetext{
${ }^{1}$ E isso independe da abordagem com a qual se está trabalhando na educação física, isso é dito para que não fique parecendo que certa abordagem dá conta dessa avaliação e a outra não, ou que certa abordagem se direciona para essa avaliação enquanto as outras não. Não é objetivo desse trabalho entrar no mérito das abordagens e de suas particularidades e julgar se uma e outra são capazes de realizar essa avaliação de forças, a qual está em jogo aqui. Tais forças estão sempre na dinâmica das aulas, sejam quais forem as maneiras como essas aulas são construídas.

${ }^{2}$ Utiliza-se a palavra atuante invés de ator nesse texto para enfatizar que há atuações humanas e não-humanas nos campos sociais e ambas produzem efeitos.
} 
estados de coisas para dizer que o mesmo cheiro é sentido diferentemente entre os seres. No entanto, há ainda outra complicação. Determinado cheiro pode produzir sentidos também diversos. Eisso não só pelas afecções que demandam do sentido olfativo, tampouco pelos julgamentos delas decorrentes - um cheiro ruim, um cheiro bom (o que também não é unanimidade). Um cheiro pode criar uma lembrança, pode modificar o sabor de uma comida, pode resultar numa cópula (cheiro do cio), pode levar a lugares inimagináveis.

\section{A afecção, pois, não só é o efeito instantâneo de um corpo sobre o meu mas tem também um efeito sobre minha própria duração, prazer ou dor, alegria ou tristeza. São passagens, devires, ascensões e quedas, variações contínuas de potência que vão de um estado a outro: serão chamados afectos, para falar com propriedade, e não mais afecções (DELEUZE, 1997, p. 157).}

Uma força, portanto, tem a ver com os afetos de um corpo. Ao atravessar um corpo que é, antes de qualquer coisa, aquele que possui o poder de afetar e ser afetado, uma força é capaz de aumentar ou diminuir a potência desse corpo de agir. Aumenta quando a força é repleta de afetos alegres e diminui quando são afetos tristes. Essas são formulações espinosistas que Gilles Deleuze toma para si em diversos pontos de sua obra e que são especialmente significativas para essa escrita.

Com relação à avaliação, ela está ligada a essa potência que varia. Quando um corpo é capaz de selecionar o que lhe convém, ele tem sua potência aumentada, da mesma forma que tem sua potência diminuída por encontros com afetos tristes. Por isso a avaliação das forças tanto para a seleção como para quando essa não é possível, ou seja, em encontros furtivos, ainda sim a avaliação auxilia para criação de saídas impensadas.

Tomou-se o caso da autonomia por conta de seu "ar" de senso comum para a educação escolar. Quando a pensamos com esses critérios da avaliação de forças e de suas variações, bem como das diferentes dinâmicas que compõem o espaço e tempo sociais, ela deixa de ser um fim em si mesma, deixa de se constituir como uma abstração, e se torna uma participante dentro da atualidade dos encontros e na intensidade dos afetos.

Um caso entre muitos em que uma abstração toma lugar de um fim e se torna um senso comum inquestionável.

O problema que essa escrita enfrenta é de pensar sobre a função social da escola e o papel da educação física dentro dela, bem como erigir alguns temas na tentativa, não de esgotar o problema, mas criar formas de aproximação com ele. 
Foram introduzidas algumas ideias que compõem esse trabalho e, mais do que isso, algumas modulações do pensamento para ponderar uma escola e uma educação física. Ao questionar aquilo que se constitui como incontestável é preciso criar um corpo o qual é capaz de se afetar diferentemente pelo instituído, sentir o mesmo cheiro com outro nariz ou pés estranhos.

\section{Uma questão de aprender}

Uma das dificuldades que a escola e a educação física possuem é com relação à aprendizagem. Não há dúvidas de que ela faz parte desses territórios, no entanto, como, afinal, ela pode ser pensada?

Ora, a aprendizagem nada mais é do que a aquisição de um saber, aquisição de um conhecimento. Mas será que ela se resume a apenas isso? Será que essa é a única maneira de pensar a aprendizagem?

Há algumas portas de entrada para pensá-la. Nessa escrita a escolha é a tentativa de entendê-la, desde a educação física, com a filosofia de Gilles Deleuze e alguns aliados.

Partindo do instituído a aprendizagem tem a ver com certa meta incluída no planejamento, a qual, através da avaliação, pode ser, então, medida. Busca-se, nas aulas, que todos os alunos aprendam aquilo que está sendo passado, incluindo estratégias pedagógicas para esse alcance.

Durante a formação inicial em educação física uma questão bastante comum é de os alunos não saberem como se ensina algo a alguém. Estranha dúvida se olhar para essa ideia instituída de aprendizagem, já que nela tudo parece tão linear. Talvez aí já haja uma desconfiança de que aprender seja mesmo algo tão comum, e que os indivíduos aprendem da mesma forma.

Também o ensinar possui seu contorno linear, ao ser pensado como transmissão de conhecimento do professor para o aluno. Traçado retilíneo disposto pelo hífen que liga a expressão ensino-aprendizagem, ligando essas duas dimensões, tornando-as indiscerníveis.

Romper com essa linearidade não diz só respeito a uma resistência em relação ao que se entende por aprendizagem e o ato de ensinar, mas também possui como intuito sempre questionar: Se a função social da escola e da educação física está relacionada com a aprendizagem, como ela é engendrada nesses espaços e tempos sociais? Pergunta que se coloca nesse texto, mas que se insere num movimento de permanente questionamento. 
Nas particularidades e especificidades da educação física, o que significa aprender em educação física? O que está em jogo quando se aprende algo em educação física? Quais são, pois, os parâmetros que dizem da aprendizagem de um corpo? São parâmetros do desenvolvimento motor? Tais parâmetros são capazes de dizer de uma aprendizagem? Afinal, quais são os sentidos de uma aprendizagem?

Talvez as possíveis respostas para essas perguntas necessitem sempre estarem sendo revistas, reorganizadas, repensadas, pois a fixidez não ajuda muito nas aprendizagens nem nos fundamentos, que serão tratados no item posterior. Fixidez que coagularia os conhecimentos e aquilo que eles podem. Fixidez que mumificaria os corpos e aquilo que eles podem.

Também não se trata de negar determinadas tentativas de respostas porque elas se colocam dentro de certa construção de conhecimento, ou seja, negar as dimensões biológicas por elas não alcançarem a complexidade do que significa aprender. Na verdade, aumentar o número de versões de um mundo (LATOUR, 2008) possa ser muito mais interessante para dizer de um corpo que aprende do que restringir parâmetros e teorias unidirecionais.

Uma resposta bem ampla para essas perguntas poderia ser que a educação física é aquela que, no ambiente escolar, produz sentidos com a cultura corporal. Assumir essa premissa como fundamental pode ser interessante para pensar a área e sua função dentro da escola.

No entanto, essa escrita difere da ideia de que a escola é aquela instituição social que é responsável por inserir os alunos e alunas na cultura, no conhecimento. A escola não insere os alunos e alunas na cultura, na escola se produzem culturas, se confrontam culturas.

Essa ideia de cultura será também tratada, na relação com os fundamentos, por outros vieses no item posterior, no entanto, é importante frisar que alguns autores importantes da área da educação física, como João Batista Freire, Jocimar Daolio, o coletivo de autores, Elenor Kunz e Mauro Betti ${ }^{3}$, direcionaram seus olhares para uma ideia de cultura com a qual fizeram ressonância. A discussão que se coloca nesse item, mesmo que um tanto ligeira por conta do espaço dessa escrita, possui como mar navegável uma antropologia (assim como Jocimar Daolio, mas conversando com autores diferentes) para o pensamento com a cultura, uma vez que se vislumbram nessas águas outros movimentos para pensá-la, na verdade outros modos de

\footnotetext{
${ }^{3}$ Para falar de apenas alguns nomes, correndo o risco de deixar de fora muitos outros. 
pensamento com uma cultura. Almeja-se, assim, contribuir com a formação de relações entre os termos: cultura, escola e educação física - pensando, especialmente, com a aprendizagem.

Em A invenção da cultura, o antropólogo norte americano Roy Wagner (2012) apresenta um ponto de vista em que a antropologia se coloca como aquela que observa fenômenos humanos, todavia numa perspectiva que é criada nesse encontro - antropólogo e fenômeno. Assim, a cultura não é algo localizável e o antropólogo é aquele que vai a campo para olhá-la e depois contá-la, isso a tornaria extremamente fixa e já dada. Diferentemente, a cultura, na perspectiva desse autor, é uma maneira de fazer as coisas (alheias depois as suas próprias), ela é, portanto, um modo de existência.

"No ato de inventar outra cultura, o antropólogo inventa a sua própria e acaba por reinventar a própria noção de cultura" (WAGNER, 2012, p. 43). É importante frisar que a noção de invenção nele tratada não diz respeito a uma oposição entre real e imaginário, tampouco falso e verdadeiro, compreende-se "a invenção como um processo que ocorre de forma objetiva, por meio de observação e aprendizado, e não como uma espécie de livre fantasia” (WAGNER, 2012, p. 43). Ela difere, então, da descoberta, da manipulação de uma matéria inativa, da fixação por um produto acabado, sua apreensão está voltada para um processo, como já foi dito, de contínua mudança e da colocação de forças em jogo.

A invenção da cultura não é a representação daquilo que existe e está dado em si, tampouco a criação a partir do nada - em ambos os casos a cultura em que se entra em contato não afeta e não leva a pensar sobre os modos de vida. Essa invenção de que escreve Wagner tem a ver com uma negociação entre convenção e diferenciação de toda uma simbologia social. Para o autor, as simbolizações dotadas de significados mobilizam forças inventivas nos meios sociais em que são dramatizadas, em suas palavras há uma "deriva” de significados culturais em "atos criativos" "de modo a redirecionar continuamente a força de expressões anteriores e subsumi-la em novas construções" (WAGNER, 2012, p. 23-24), por isso se pode falar em mobilização do pensamento com os modos de vida, porque o processo de invenção é incessante.

Sobre o aprender, a ideia de que se experimenta algo, o qual se torna matéria-prima da invenção da cultura, tem a ver com um aprendizado dela, bem como a criação de uma maneira de expressar esse aprendizado. Em antropologia, "é por isso que vale a pena estudar outros povos, porque toda compreensão de uma outra cultura é um experimento com nossa própria cultura" (WAGNER, 2012, p. 61). Mas também se pode pensar não no estudo de outros povos, mas 
PONTIN, Vivian Marina Redi. Uma aprendizagem lenta da vida.

naquilo que se coloca como conteúdo disciplinar na escola, compreendendo essa cultura escolar ali construída, inventada, como um experimento com a cultura vivenciada pelos atuantes desse espaço e tempo escolar. Só que

[...] não podemos apelar para a força de algo chamado 'tradição', 'educação' ou orientação espiritual para dar conta da continuidade cultural - ou, na verdade, da mudança cultural. As associações simbólicas que as pessoas compartilham, sua 'moralidade', 'cultura', 'gramática' ou 'costumes', suas 'tradições', são tão dependentes de contínua reinvenção quanto as idiossincrasias, detalhes e cacoetes que elas percebem em si mesmas ou no mundo que as cerca. A invenção perpetua não apenas as coisas que 'aprendemos', como a língua ou boas maneiras, mas também as regularidades de nossa percepção, como cor e som, e mesmo o tempo e o espaço (WAGNER, 2012, p. 138, grifos do autor).

Portanto, lidar com esses conteúdos na escola não se trata, nessa dimensão, de garantir uma continuidade da cultura, sua preservação, como se os alunos apenas tomassem para si aquilo que já está construído pela sociedade em que vive, perpetuando-a e como se fosse possível preservar a cultura intacta. No entanto, não é de se descartar as convenções e regularidades, e Wagner não o faz, como já foi dito, não se cria, não se inventa a partir do nada. Marcio Goldman (2011), numa resenha sobre esse livro de Wagner, destaca a importância da convenção e da diferenciação nele, "talvez" como "conceitos centrais do livro" (p. 207) e escreve: "Simbolizar é sempre utilizar de forma 'diferenciada' símbolos que fazem parte de uma 'convenção', e é apenas o peso respectivo de cada procedimento em cada ato simbólico que varia” (GOLDMAN, 2011, p. 207, grifos do autor). A cada vez que o atuante age, utiliza elementos de forma diferenciada seja para entrar numa convenção ou sair dela, por isso sempre se inventa a cultura, se inventa um modo de vida.

Outra ideia que o autor trata a respeito do aprender é que a "invenção é sempre uma espécie de 'aprendizado', e o aprendizado é invariavelmente um ato de invenção, ou reinvenção tanto que é de pouca ajuda falar do aprendizado como um 'processo', ou dividi-lo em 'estágios'" (WAGNER, 2012, p. 147, grifos do autor). Ideia que cria uma ferida diante de muitas teorias da aprendizagem, que a veem nesse âmbito dos estágios, especialmente pensando com a educação física. Uma vez mais não se joga fora aquilo que possui uma regularidade, no entanto, e isso é experimentado muitas vezes na educação física, há sempre algo que escapa, outro invento.

Essas linhas não esgotam aquilo que a invenção de Roy Wagner pode, apenas burila uma contribuição, afinal na medida em que se inventa uma cultura, a cada vez, portanto, não se trata de sua reprodução, tampouco transmissão, a escola e a educação física são espaços e tempos em 
que se pode inventar uma cultura - uma experimentação corpórea de uma cultura corporal escolar de educação física, em que o foco intenso nas regularidades dá lugar ao questionamento daquilo que essa invenção, a cada vez, faz funcionar.

Virginia Kastrup (2005) também coloca a aprendizagem ao lado da invenção, investigando o campo de duas políticas distintas: a da recognição, em que o conhecimento é uma questão de representação e a da invenção, uma abertura da atenção, não reduzida à mera captação de coisas do exterior e utilitária para a realização de tarefas, e na qual os problemas não se esgotam em suas soluções. Nessa toada, a aprendizagem enquanto produção de subjetividade se liga à invenção na produção de si e de um mundo. "Aprender é, então, em seu sentido primordial, ser capaz de problematizar a partir do contato com uma matéria fluida, portadora de diferença e que não se confunde com o mundo dos objetos e das formas" (KASTRUP, 2005, p. 1277), por isso seu não fechamento, uma vez que problematizar a cada vez essa composição do mundo, "reiniciar, retornar, renovar, reinventar, reiterar, recomeçar" (p. 1279), fazer circular, faz parte de um movimento mais do que um acabamento.

A política de recognição, que toma o conhecimento como representação do mundo, direciona-se para a aquisição e transmissão de informações. Nela há uma convergência entre os sentidos do corpo e do mundo, uma vez que o que se vê participa de relações de poder para ser visto, no entanto essas relações são escamoteadas em favor da aquisição de um saber já pronto, já dado - ver o visto, ou o já visto.

Na tentativa de combater tal política, o desafio que se coloca não é o da captura da “atenção do aluno para que ele aprenda, mas promover nosso próprio aprendizado da atenção às forças do presente, que trazem o novo em seu caráter disruptivo. Pois ensinar é, em grande parte, compartilhar experiências de problematização" (KASTRUP, 2005, p. 1287).

A invenção de que falava Roy Wagner (2012) e de que fala Virginia Kastrup (2005), então, que se conecta diretamente com uma aprendizagem, uma questão de aprender, e que pode se ligar com a produção de sentidos com a cultura corporal, tem a ver também com a produção de subjetividade, uma vez que a ideia é de colocar em jogo as várias culturas produzidas. Se os conteúdos da educação física são os jogos, esportes, ginásticas, danças, lutas etc., ao aprender, os atuantes do espaço-tempo escolar colocam em movimento os vários sentidos produzidos com esses conteúdos, diferentemente de apreendê-los da maneira como estão inscritos previamente no mundo. "Aprender é, então, fazer a cognição diferenciar-se permanentemente de si mesma, 
engendrando, a partir daí, novos mundos" (KASTRUP, 2005, p. 1282) - a produção de subjetividade é a produção de modos de existência, modos de vida dos corpos nesses novos mundos. Mais distante de aprender o que é o futebol, talvez o espaço da educação física possa participar do entendimento e desentendimento daquilo que o futebol faz funcionar.

\section{Uma questão de fundamento}

Dentro do campo problemático da formação inicial de professores de educação física, há alguns termos que colocam em jogo relações concernentes à escola enquanto espaço social. Um deles é a aprendizagem, tratada no item anterior, e essa parte da escrita dedicar-se-á ao termo fundamento. Eles não são exclusivos do ambiente escolar, tampouco abarcam as complexidades nele engendrado, também possuem em seu bojo a convocação de outros termos, tal como o ensino para a aprendizagem, e chão para fundamento.

Não haverá uma exposição de como o fundamento se insere na educação física escolar, assemelhando-se a uma aplicação, ou detecção. Não é uma questão de estabilização. Dedica-se um pensamento em camadas de formação dispostas entre o que se entende por fundamentos, e uma atenção aos afetos que percorrem os corpos no espaço social escolar.

Etimologicamente fundamento, do latim fundamentum se entende como um conjunto de princípios iniciais a partir dos quais se elabora, se estabelece ou se cria algo. Tal etimologia se conjuga numa ideia de processo, mais do que num alicerce imóvel, ou numa estrutura fixa, para aquilo que dá sentido ao fundamento. Nesse processo, em que um fundamento se coloca como aquele que possibilita um começo, há uma maneira de olhar para a formação de professores, um

movimento iniciado pelos fundamentos ali presentes, os quais não são fixos, uma vez que é preciso inseri-los no campo problemático do território escolar.

Há um esforço nesse lugar incerto do movimento. Ou seja, nem os fundamentos que iniciam essa formação estão dados, tampouco o território em que tais fundamentos participarão. É em um chão movediço que as aprendizagens, fundamentos, corpos e afetos se metamorfoseiam e fazem com que a educação física seja, ali na escola, sempre reinventada a cada vez, sempre performatizada por aquilo que o território escolar coloca em jogo.

Por isso a ideia de camadas de formação, como se fossem camadas de sabores que o paladar de um professor vai experimentando a cada vez com seus alunos e aquilo que participa 
daquela determinada aula. A pergunta que se coloca nesse movimento é o que a educação física, ali, faz funcionar?

Retomando a ideia de que a educação física produz sentidos com a cultura corporal no ambiente escolar - questão fundamental - seus fundamentos, portanto, possuem um comprometimento, uma ancoragem nessa produção.

Essas camadas de formação podem ser colocadas como pedaços de cultura que vão se impregnando nos corpos pelos espaços e tempos sociais, formativos e outros, que se percorrem. Porque também a cultura corporal, a qual se quer produzir sentidos, não está dada para que o movimento seja apenas de um acesso a ela. Há também nela pedaços de várias culturas que se impregnam, dando-lhe contornos diferenciados.

Quando Tarcísio Mauro Vago (1999) escreve sobre uma cultura escolar de educação física, há uma ressonância com essa produção de sentido com a cultura corporal, uma vez que ela passa por um processo transformativo para adentrar no espaço e tempo escolar. É preciso analisar aquilo que nela está impregnado das culturas, ou seja, tomando-se determinado conteúdo da cultura corporal, faz-se necessário entender as dinâmicas sociais nas quais esse determinado conteúdo está inserido e embebido de características, trazer isso à tona por aquilo que os alunos e alunas trazem de suas experiências com aquele conteúdo, bem como é papel do professor oferecer perspectivas dele, portanto, nuances de sua circulação nesses outros espaços sociais, para, então, juntos - professor e alunos - construírem uma forma de aproximação desse conteúdo dentro de uma aula de educação física, inserida nas demandas de sua função social escolar.

Visto isso, a atenção a essas transformações que vão sendo engendradas com e pela cultura corporal é um fundamento para a educação física escolar. Também é preciso preocupar-se com essa aproximação dos conteúdos da cultura corporal na escola, porque ela é diferenciada da aproximação que se pode ter em outros espaços e tempos sociais, há uma singularidade nessa experiência.

Esta dupla exigência de seleção na cultura e de reelaboração didática faz com que não se possa apegar-se à afirmação geral e abstrata de uma unidade da educação e da cultura: é necessário matizar e especificar, isto é, construir uma verdadeira problemática das relações entre escola e cultura (FORQUIN, 1993, p. 14).

Cultura corporal poderíamos acrescentar a esse lúcido parágrafo de Jean-Claude Forquin (1993). Essa atenção fundamental para as transformações relaciona-se com problematizar o 
porquê da seleção de tais e tais conteúdos para comporem o currículo da educação física escolar.

Atenção e seleção, substantivos femininos que podem colocar em jogo gestos fundamentais para a educação física. Com relação à atenção pode-se voltar à Virginia Kastrup (2005) quando ela diferencia as aprendizagens pelas relações de recognição e invenção. Sem criar repetições, o que se gostaria de salientar é o desafio que a autora levanta ao enveredar por uma política da invenção - "O desafio da implementação dessa política é conceber práticas que viabilizem o desencadeamento de processos de problematização que não se esgotem ao encontrar uma solução" (KASTRUP, 2005, p. 1282). Portanto, atentar-se às produções de sentido que as aulas engendram na invenção das culturas corporais, logo, uma atenção que se volta para os problemas que se encontram nessas invenções, mais do que para solucionar a questão do que é a cultura corporal ou do que é cada um de seus conteúdos.

Com relação à seleção, já que a relação entre escola e cultura, como lembrou Forquin (1993), não está dada, e ela é matizada a cada encontro desses termos, a seleção não tem a ver apenas com os conteúdos, mas também com aquilo que foi colocado na introdução sobre a avaliação de forças e a seleção daquilo que convém. Uma vez selecionado o conteúdo, e ele sofrerá uma série de transformações ao longo das aulas, a atenção deve estar voltada para as forças que estão em jogo nesse processo formativo e a seleção dos atuantes para aquilo que convém ou não investir, nas importâncias em jogo, naquilo que essas forças e seleções fazem funcionar. Mas o que essa seleção tem a ver com a relação matizada entre escola e cultura?

Tornando essa escrita enquanto construção de um pensamento, uma vez que a cultura é invenção de modos de vida e uma vida se compõe entre forças que aumentam e diminuem a potência de agir de um corpo. E também que a aprendizagem liga-se a essa invenção, já que, ao aprender, se colocam as forças do mundo em movimento, seu fundamento, seu chão, pode-se dizer, está na avaliação dessas forças e, consequentemente, na seleção, porque se elege aquilo que mais convém ao corpo. Escola e cultura. Aprendizagem, fundamento e seleção. A escola está para um espaço e tempo em que se compartilham culturas, em que as aprendizagens podem brindar e isso depende muito daquilo que se seleciona ao estar presente nesse universo. Matizar a relação entre escola e cultura prolifera seus sentidos, já que imersas na caótica das forças que os corpos põem em jogo em suas seleções.

Deleuze dizia em Proust e os signos (2010) que não se sabe como alguém, um aluno, de repente se torna bom em latim. Quais são, questiona, os signos inconfessáveis, amorosos que 
PONTIN, Vivian Marina Redi. Uma aprendizagem lenta da vida.

participam dessa aprendizagem? Para o filósofo, "Nunca se aprende fazendo como alguém, mas fazendo com alguém, que não tem relação de semelhança com o que se aprende" (p. 21, grifos do autor). Por isso Virginia Kastrup (2005) frisa a diferença da aprendizagem como recognição e como invenção, porque a aprendizagem, seu chão, está imerso na heterogeneidade, logo a escola como espaço e tempo de uma aprendizagem só poderia ser um lugar de diferenças, mais do que de semelhanças. E isso não significa que as oposições ali reinam, mas de que a seleção possa ser capaz de incentivar alianças as mais inusitadas.

Ainda sobre a seleção, Jean-Claude Forquin levanta uma questão importante:

Que é pois que, nos conteúdos vivos da cultura, nas significações que atualmente têm poder de interpelar nossos pensamentos e de regular nossas existências, pode ser considerado como tendo um 'valor educativo' ou uma pertinência social suficientes para justificar os gastos de todos os tipos exigidos por um ensino sistemático e mantido pelo Estado? (1993, p. 16, grifo do autor).

Não apenas justificar os gastos, mas em algumas páginas posteriores: "Em quê o mundo muda, por que, e em quais direções?” (FORQUIN, 1993, p. 19). Perguntar-se pelo quê a seleção está fazendo circular, essa talvez seja uma das tarefas dos atuantes do espaço e tempo escolar.

Outra questão fundamental para educação física, tanto na formação como em sua inserção na escola, é que o professor precisa interessar-se por aquilo que está botando em jogo numa aula - "É preciso achar a matéria da qual tratamos, a matéria que abraçamos, fascinante [...] É necessário chegar ao ponto de falar de algo com entusiasmo" (DELEUZE, [s/d.], entrevista em vídeo). Porque se nem ele achar interessante, quiçá os alunos e alunas ali no calor da aula.

Também Jean-Claude Forquin ${ }^{4}$ compartilha dessa ideia, em outras palavras: "Esta noção de valor intrínseco da coisa ensinada, tão difícil de definir e de justificar quanto de refutar ou rejeitar, está no próprio centro daquilo que constitui a especificidade da intenção docente" (FORQUIN, 1993, p. 9).

É bom ressaltar que essa ideia de interesse não propriamente diz respeito a uma escolha direcionada pelo indivíduo só. Em sua própria etimologia, o interesse significa aquilo que está entre, então participa de uma subjetividade compartilhada, de uma constituição de algo comum.

\footnotetext{
${ }^{4}$ Nessa obra, ainda insiste, não se sabe se por conta da tradução do francês para o português, na ideia de transmissão dentro do universo escolar. Não se compartilha, aqui, dessa ideia, porque o que se gostaria de pensar é em outros verbos para essa relação entre professor/a e aluno/aluna, o que reflete na questão que baliza o texto sobre a função social da escola e da educação física. A metáfora de outros verbos procura ampliar essa relação que acontece na escola, tirando o peso das hierarquias e das direções unívocas que adjetivam tal relação, bem como, também essa metáfora, diz respeito ao que ganha de sentidos aprendizagem e fundamento.
} 
Assim, ao querer pensar numa questão de fundamento, longe de amarras metodológicas, didáticas, conteudísticas etc., busca-se embebê-la, chão que é, da heterogeneidade que pode lhe compor, das camadas de formação que produzem diferentemente os atuantes, das atenções ao que pode o corpo na caótica "tensão permanente" (VAGO, 1999) das culturas, das seleções enleadas das forças de um mundo. Um fundamento inconformado.

\section{Da imprevisibilidade do fim}

Tomou-se o caso da autonomia para introduzir uma construção de pensamento. Nesse pequeno espaço de uma escrita, essa construção se dispôs, diante dos critérios da avaliação de forças e suas variações, a adentrar nos terrenos da escola e da educação física. Neles foram chamados alguns participantes, a aprendizagem e o fundamento, para ponderar, a partir da atualidade dos encontros e da intensidade dos afetos, as questões de uma função social para esses terrenos.

Questionar-se como a aprendizagem é engendrada foi uma tentativa de escapar de ideias cristalizadas do que significa aprender, especialmente aquela de uma transmissão. Tiveram papel importante nesse questionamento a invenção de uma cultura com Roy Wagner (2012) e a diferença entre recognição e invenção de Virginia Kastrup (2005). Com esses aliados pode-se entender que a invenção é uma espécie de indagação daquilo que as convenções e diferenciações colocam em jogo. E que aprender, tal como inspira Deleuze, não é um processo linear e composto de estágios, não se sabe como alguém se torna bom em latim, uma aprendizagem coloca as regularidades e lacunas da percepção como aquelas que inventam uma cultura, portanto, um modo de vida.

Tendo a educação física como produção de sentidos com a cultura corporal, seu fundamento, se chão tem uma ancoragem nessa produção. Ali, atenção e seleção foram palavras elegidas para dizer de uma aliança que pode favorecer ou não esse modo de vida que se cria ao aprender.

Atentar-se ao que as aulas de educação física fazem funcionar, portanto atentar-se para os problemas que as tensões entre culturas viabilizam - por exemplo, nas relações de gênero na aproximação com determinado conteúdo da cultura corporal. Veja que há uma diferença entre dizer que os conteúdos por si só são capazes de trazer à tona conflitos sociais e que o espaço da 
escola é de sua reprodução em menor escala entre aspas, e lá, assim, é o lugar privilegiado para que surjam soluções para as desigualdades e suas demandas e consequências. Esse caminho muito se parece com aquele no qual pelo argumento de tirar as crianças e jovens das ruas, afinal é nas ruas que os problemas se encontram, devem-se ofertar programas esportivos em lugares diversos. Tudo isso para dizer que não são os conteúdos em si que trazem as soluções para tais querelas sociais, tampouco a escola é a redentora e salvadora da nação apenas por ser escola.

Frisando novamente que a escola é espaço e tempo de conflito, de atrito entre culturas, então, se os combates surgem, obviamente é porque a escola está inserida num contexto social mais amplo, a questão é como lidar com isso. Quando se diz que não se trata do conteúdo em si é porque, na verdade, a atenção deve estar voltada para aquilo que ele faz funcionar, quais são, pois, os sentidos produzidos com esse ou aquele conteúdo, com esse ou aquele método, com essa ou aquela didática, enfim com as iniciativas tomadas nesse espaço e tempo escolar.

Por que, afinal, insistir em determinados conteúdos? Em determinadas iniciativas? Como lembrou Roy Wagner, não adianta apelar para tradição e educação na continuidade ou mudança da cultura, seja lá qual for, a cultura é uma invenção e reinvenção, a todo o momento, coletiva e ao mesmo tempo individual, dentro de uma dinâmica produção de sentidos para os modos de vida que são experimentados. Por isso, com relação às querelas sociais, não há previsibilidade possível já que não se sabe como e o que se aprende, quiçá saber das forças que estarão em jogo em cada tentativa de solucionar ou prevenir tais problemas.

O que se gostaria de pensar com as linhas desenhadas ao longo dessa escrita é de que na escola e na educação física a ideia não é chegar em soluções, mas problematizar os funcionamentos, encontrar esses caminhos problematizadores - selecionar - é papel, é função da educação física escolar. Portanto, dar a ver certos funcionamentos da cultura corporal na sociedade e o que produzem de sentido. Uma sociedade que não está além dos muros da escola, mas dentro de cada atuante sendo produzida a todo instante.

Por último, uma questão metodológica, por que escolher a filosofia de Gilles Deleuze para falar da aprendizagem?... ainda mais para pensar uma educação física? Em um de seus cursos sobre Spinoza, Deleuze (2009) diz que um filósofo talvez seja aquele que inventa maneiras de perceber. Então, ainda escolher esses intercessores (Deleuze, Spinoza, Filosofia) é interessar-se por inventar maneiras de perceber a aprendizagem. Talvez isso tenha a ver com o trabalho do professor - investir nessa percepção das aprendizagens. 
Ter Gilles Deleuze como inspiração e aliado não significou, aqui, ficar repetindo sua filosofia, aplicando seus conceitos. Bem que se quis trazê-lo ora enquanto autor e fazer referência aos seus escritos, ora enquanto potência de pensamento e a possibilidade de pensar diferentemente aquilo que já se via, todavia ainda invisível, enfim dar a ver algo com essa escrita.

Nesse sentido, não são com certezas que se constrói uma boa formação, mas com atenção voltada para aquilo de imprevisível que acontece na perenidade do cotidiano escolar. Porventura inventar maneiras de lidar com as contingências e circunstâncias de habitar um mundo, suas percepções, aprendizagem lenta com uma vida.

\section{Referências}

DARIDO, Suraya; RANGEL, Irene Conceição Andrade. (Coord.). Educação física na escola: implicações para a prática pedagógica. 2. ed. Rio de Janeiro: Guanabara Koogan, 2011.

DELEUZE, Gilles. L'abécédaire de Gilles Deleuze: entrevistas com Claire Parnet. Realização de P.-A. Boutang. Paris: Montparnasse; Liberation, [s/d.].

DELEUZE, Gilles. Spinoza e as três “éticas”. In: CRÍTICA e clínica. São Paulo: Ed. 34, 1997.

DELEUZE, Gilles. Cursos sobre Spinoza (Vincennes, 1978-1981). 2. ed. Fortaleza: EdUECE, 2009.

DELEUZE, Gilles. Proust e os signos. 2. ed. Rio de Janeiro: Forense Universitária, 2010.

FORQUIN, Jean-Claude. Escola e cultura: as bases sociais e epistemológicas do conhecimento escolar. Porto Alegre: Artes Médicas, 1993.

GOLDMAN, Marcio. O fim da antropologia. Novos estudos CEBRAP, São Paulo, n. 89, p. 195-211, mar. 2011. Disponível em: <http://www.scielo.br/scielo.php?script=sci_arttext\&pid=S010133002011000100012>. Acesso em: 1 fev. 2018.

KASTRUP, Virgínia. Políticas cognitivas na formação do professor e o problema do devir-mestre. Educação e Sociedade, Campinas, v. 26, n. 93, p. 1273-1288, set./dez. 2005.

LATOUR, Bruno. A esperança de Pandora: ensaios sobre a realidade dos estudos científicos. Bauru, SP: EDUSC, 2001.

LATOUR, Bruno. Como falar do corpo? A dimensão normativa dos estudos sobre a ciência. In: NUNES, João Arriscado; ROQUE, Ricardo. (Org.). Objetos Impuros: experiências em estudos sobre a ciência. Porto: Edições Afrontamento e autores, 2008.

TAVARES, Gonçalo M. O homem ou é tonto ou é mulher. São Paulo: Casa da Palavra, 2005.

VAGO, Tarcísio Mauro. Intervenção e conhecimento na escola: por uma cultura escolar de educação física. In: GOELLNER, Silvana Vilodre. (Org.) Educação física / ciências do esporte: intervenção e conhecimento. Florianópolis: Colégio Brasileiro de Ciências do Esporte, 1999.

WAGNER, Roy. A invenção da cultura. São Paulo: Cosac Naify, 2012. 
PONTIN, Vivian Marina Redi. Uma aprendizagem lenta da vida.

\author{
Vivian Marina Redi Pontin \\ UNICAMP | multiTÃO-Labjor-Unicamp \\ Campinas | SP | Brasil. Contato: vivian_marina@yahoo.com.br \\ ORCID 0000-0003-3984-2216
}

Artigo recebido em: 23 mar. 2018 e aprovado em: 2 maio 2018. 